\title{
Difference in the color stability of direct and indirect resin composites
}

\author{
Yong-Keun LEE ${ }^{1}$, Bin YU², Ho-Nam LIM³ ${ }^{3}$ Jin Ik LIM
} 1- DDS, PhD, Senior Scientist, Institute for Clinical Performance of Biomaterials (ICPB), Seoul, Korea.
2- PhD, Assistant Professor, State Key Laboratory of Multiphase Complex Systems, Institute of Process Engineering, Chinese Academy of Sciences, Beijing, China.
3- DDS, PhD, Professor, Department of Dental Materials and Center for Dental Materials, Dental School, Kyung Hee University, Seoul, Korea.
4- PhD, Principal Researcher Department of Biomedical Engineering and Healthcare Industry Research Institute, College of Medicine, Kyung Hee University,
Seoul, Korea.

Corresponding address: Dr. Yong-Keun Lee, DDS, PhD - Institute for Clinical Performance of Biomaterials - \#202, Seokwang Art BD., 44-17, Jamwon-Dong, Seocho-Gu - Seoul, Korea - Phone/Fax: 82-2-6465-3470 - e-mail: ykleedm@gmail.com

Received: June 24, 2009 - Modification: August 19, 2009 - Accepted: February 16, 2010

\section{ABSTRACT}

$\mathrm{I}^{\mathrm{r}}$

ndirect resin composites are generally regarded to have better color stability than direct resin composites since they possess higher conversion degree. Objective: The present study aimed at comparing the changes in color $(\Delta \mathrm{E})$ and color coordinates $(\Delta \mathrm{L}, \Delta \mathrm{a}$ and $\Delta \mathrm{b}$ ) of one direct (Estelite Sigma: 16 shades) and 2 indirect resin composites (BelleGlass NG: 16 shades; Sinfony: 26 shades) after thermocycling. Material and Methods: Resins were packed into a mold and light cured; post-curing was performed on indirect resins. Changes in color and color coordinates of 1-mm-thick specimens were determined after 5,000 cycles of thermocycling on a spectrophotometer. Results: $\Delta \mathrm{E}$ values were in the range of 0.3 to 1.2 units for direct resins, and 0.3 to 1.5 units for indirect resins, which were clinically acceptable $(\Delta \mathrm{E}<3.3)$. Based on t-test, $\Delta \mathrm{E}$ values were not significantly different by the type of resins $(p>0.05)$, while $\Delta L, \Delta a$ and $\Delta b$ values were significantly different by the type of resins $(p<0.05)$. For indirect resins, $\Delta E$ values were influenced by the brand, shade group and shade designation based on three-way ANOVA $(p<0.05)$. Conclusion: Direct and indirect resin composites showed similar color stability after 5,000 cycles of thermocycling; however, their changes in the color coordinates were different.

Key words: Color. Resin composites. Dental resins. Dental materials. Dental prosthesis coloring.

\section{INTRODUCTION}

Resin-based indirect restorative systems were developed as possible alternatives to metallic or ceramic-based restoratives ${ }^{2}$. However, concerns as to wear resistance, color stability, expansion/ contraction and sensitivity of these restorations still remain ${ }^{11}$. Apparent disadvantage of resin-based systems stems from the fact that all resins are inherently more porous than ceramics; therefore, there is a greater propensity for these materials to stain or discolor over time and to accumulate plaque 2,24 . Clinical trial investigating the color stability of indirect resin composites showed that even after $1-2$ years, verifiable and visible changes in color occurred ${ }^{24}$.

Color of resin composites is determined not only by more macroscopic phenomena such as matrix and filler composition and filler content, but also by relatively minor pigments additions and potentially by initiator system and filler coupling agent ${ }^{15}$. Color changes of resin composites have been attributed to a wide variety of possible causes, such as chemical degradation, oxidation of the unreacted carbon double bonds, stain accumulation, dehydration, water sorption, leakage, poor bonding and surface roughness ${ }^{6,9,12-14,23,24}$. Color changes of resin composites are due to exogenous or endogenous reasons $6,9,24$. Among them, more important for the entire color stability of a light-curing material is the internal color changes, which mainly depend on the photoinitiator system as well as on the applied form and time-span of polymerization ${ }^{13,14}$. Color stability of resin composites under various physicochemical conditions improved when materials showed low water sorption, high filler-resin ratio, reduced 
particle size and hardness, and an optimal fillermatrix coupling system ${ }^{6}$.

There are arguments on the threshold color difference levels based on instrumental color measurements that can be visually perceivable or clinically acceptable $e^{8,25}$. However, the clinically acceptable value for color difference in dental materials is assumed to be $\Delta E \leq 3.3^{25}$. Based on previous color stability studies of indirect resin composite, all tested indirect resin composite facing materials showed sufficient color stability $(\Delta \mathrm{E}<3.3)$ after UV-irradiation and storage in red wine ${ }^{17}$. However, unacceptable color changes $(\Delta \mathrm{E}>3.3$ ) were detected in indirect resin composites after accelerated aging for $300 \mathrm{~h}^{7}$ and $383 \mathrm{~h}^{28}$. It has also reported that unacceptable $(\Delta \mathrm{E}>3.3)$ discoloration was observed when indirect resin composite facings were aged in tea, coffee, mouthrinse and UV irradiation ${ }^{27}$. Therefore, it remains essential to improve the color stability of these materials.

Although there have been a number studies on the properties of indirect resin composites $7,16,17,27$, there is limited information on the difference in the color stability based on contemporary direct and indirect resin composites by the type and also by the brand and shade group of indirect resin composites. Besides, indirect resin composites are generally regarded to have better color stability than direct resin composites since they possess higher conversion degree. The purpose of this study was to determine the color stability of one brand of varied shades of direct resin composites and two brands of indirect resin composite after 5,000 cycles of thermocycling. The null hypotheses assumed in the present study were that (1) the color stability of direct and indirect resin composites is be different; (2) the color change of resin composites after aging is not acceptable $(\Delta \mathrm{E}>3.3)$; (3) the color changes of indirect resin composites after thermocycling are not influenced by the brand, shade group and shade designation in each shade group.

\section{MATERIAL AND METHODS}

One brand of direct (Estelite Sigma: ES; Tokuyama, Tokyo, Japan) and two brands of indirect resin composites (BelleGlass NG: BG; Kerr, Orange, CA, USA; Sinfony: SF; 3M ESPE, St. Paul, MN, USA) were investigated (Figure 1). Since the designations for the shade groups in both of the indirect resin composites were similar (Enamel groups of BG material and SF material, Opaceous dentin group of BG material and Dentin group of SF material, and Translucent dentin group of BG material and Transparent opal group of SF material), three corresponding shade groups in two indirect resin composites were regarded as the same shade group, namely EN, DT and TL.

Resin composites were packed into a polytetrafluoroethylene mold (12 $\mathrm{mm}$ in diameter and $1 \mathrm{~mm}$ in thickness) on a polyethylene terephthalate film. After packing the resin composite, another film was laid on the top of the specimen, and pressed with a $49 \mathrm{~N}$ load for $1 \mathrm{~min}$ to produce a uniform thickness. Specimens were light cured for $40 \mathrm{~s}$ in 3 overlapping areas from one side with a light-curing unit (Spectrum 800; Dentsply/Caulk, Milford, DE, USA) with an intensity setting of $400 \mathrm{~mW} / \mathrm{cm}^{2}$. The output of the curing light was checked with a radiometer (SDS; Kerr). After curing, specimens were removed from the mold and both films were removed.

Then, secondary curing was applied to the indirect resin composites. For BG material, specimens were post-cured in a proprietary curing chamber (BelleGlass HP Curing Unit; Kerr) following the manufacturer's instructions. For SF material, specimens were post-cured in a proprietary curing chamber (Visio Beta Vario Light Curing Unit; 3M ESPE) following the manufacturer's instructions. Five specimens were made for each shade. After curing, baseline color measurements were made after storage in $37^{\circ} \mathrm{C}$ distilled water for $24 \mathrm{~h}$. After then, thermocycling was performed for 5,000 cycles in distilled water at $5^{\circ} \mathrm{C}$ and $55^{\circ} \mathrm{C}$ with a dwell time of $15 \mathrm{~s}$.

Color was measured before and after thermocycling according to the CIELAB color scale relative to the standard illuminant D65 over a white tile (CIE $L^{*}=94.3, a=-0.1$ and $b^{*}=-0.4$ ) on a reflection spectrophotometer (Color-Eye 7000A; GretagMacbeth, New Windsor, NY, USA) after blot dry. An ultraviolet (UV) filter was positioned to $100 \%$ UV included condition with the specular component excluded (SCE) geometry. The aperture size was $3 \times 8 \mathrm{~mm}$, and illuminating and viewing configuration was CIE diffuse/8-degree geometry ${ }^{4}$. Measurements were repeated 3 times for each specimen and averaged.

Color change $(\Delta \mathrm{E})$ after thermocycling was calculated as $\Delta E=\left[(\Delta \mathrm{L})^{2}+(\Delta \mathrm{a})^{2}+(\Delta \mathrm{b})^{2}\right]^{1 / 2}$. Changes in color coordinates [CIE $L^{*}(\Delta \mathrm{L}), a^{*}(\Delta \mathrm{a})$ and $\left.b^{*}(\Delta \mathrm{b})\right]$ were calculated as 'the value after thermocycling - the value before thermocycling'. CIE $L^{*}$ is a measure of the lightness, CIE $a^{*}$ is a measure of redness (positive direction) or greenness (negative direction) and $\operatorname{CIE} b^{*}$ is a measure of yellowness (positive direction) or blueness (negative direction) of an object.

$\Delta \mathrm{E}, \Delta \mathrm{L}, \Delta \mathrm{a}$ and $\Delta \mathrm{b}$ values by the type of resin composites were analyzed by t-tests. $\Delta \mathrm{E}, \Delta \mathrm{L}$, $\Delta \mathrm{a}$ and $\Delta \mathrm{b}$ values by the shade group of resin composites were analyzed by one-way analysis of variance (ANOVA) and Scheffe's post hoc test (SPSS 12.0; SPSS, Chicago, IL, USA; $\alpha=0.05$ ). $\Delta \mathrm{E}$, 
$\Delta \mathrm{L}, \Delta \mathrm{a}$ and $\Delta \mathrm{b}$ values of indirect resin composites were analyzed by three-way ANOVA with the fixed factors of the brand ( 2 brands), shade group ( 3 groups) and shade designation in each shade group.

\section{RESULTS}

$\Delta \mathrm{E}, \Delta \mathrm{L}, \Delta \mathrm{a}$ and $\Delta \mathrm{b}$ values by the shade are presented in Figures $2-5 . \Delta \mathrm{E}$ values were in the range of 0.3 to 1.2 (mean: $0.8 \pm 0.2$ ), 0.3 to 0.9 (mean: $0.5 \pm 0.2$ ) and 0.4 to 1.5 units (mean: $0.8 \pm 0.4$ ) for ES, BG and SF material, respectively (Figure 2). $\Delta \mathrm{L}$ values were in the range of -0.3 to 0.3 (mean: $0.0 \pm 0.2$ ), -0.7 to 0.0 (mean: $-0.4 \pm 0.3$ ) and -0.5 to 0.9 units (mean: $0.5 \pm 0.5$ ) for ES, BG and SF material, respectively (Figure 3). $\Delta$ a values were in the range of 0.0 to 0.6 (mean: $0.2 \pm 0.1$ ), 0.0 to 0.1 (mean: $0.0 \pm 0.0$ ) and 0.0 to 0.3 units (mean: $0.1 \pm 0.1$ ) for ES, BG and SF material, respectively (Figure 4$). \Delta b$ values were in the range of -1.2 to -0.4 (mean: $-0.7 \pm 0.3$ ), -0.6 to

\begin{tabular}{|c|c|c|c|c|c|}
\hline Material & Group & $\begin{array}{l}\text { Group } \\
\text { code }\end{array}$ & Shade (Shade code) & Composition & Manufacture \\
\hline \multirow[t]{3}{*}{$\begin{array}{l}\text { Estelite } \\
\text { Sigma (ES) }\end{array}$} & $\begin{array}{l}\text { Basic } \\
\text { shade }\end{array}$ & ES-BS & $\mathrm{A} 1, \mathrm{~A} 2, \mathrm{~A} 3, \mathrm{~A} 3.5$ & \multirow{3}{*}{$\begin{array}{l}71 \text { vol.\% ( } 82 \text { wt.\%) of } \\
\text { silica-zirconia filler and } \\
\text { composite filler }(0.1 \text { to } \\
0.3 \mu \mathrm{m}) ; \text { Bis-GMA and } \\
\text { TEGDMA }\end{array}$} & \multirow[t]{3}{*}{$\begin{array}{l}\text { Tokuyama, } \\
\text { Tokyo, Japan }\end{array}$} \\
\hline & $\begin{array}{l}\text { Additional } \\
\text { shade }\end{array}$ & ES-AS & $\begin{array}{l}\text { Incisal (IN), B1, B2, } \\
\text { B3, B4, C1, C2, } \\
\text { Cervical (CE) }\end{array}$ & & \\
\hline & $\begin{array}{l}\text { Opaque } \\
\text { shade }\end{array}$ & $\begin{array}{l}\text { ES- } \\
\text { OS }\end{array}$ & $\mathrm{BW}, \mathrm{OA} 1, \mathrm{OA} 2, \mathrm{OA} 3$ & & \\
\hline \multirow[t]{3}{*}{$\begin{array}{l}\text { BelleGlass } \\
\text { NG (BG) }\end{array}$} & Enamel & $\begin{array}{l}\text { BG- } \\
\text { EN }\end{array}$ & 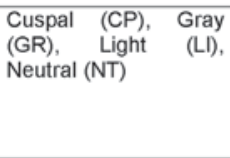 & $\begin{array}{l}70 \text { vol.\% (77 wt.\%) of } \\
\text { borosilicate glass (0.4 } \\
\mu \mathrm{m}) \text { and silica } \\
\text { nanoparticles }(50 \mathrm{~nm}) \\
\text { aliphatic resin and } \\
\text { UDMA }\end{array}$ & \multirow[t]{3}{*}{$\begin{array}{l}\text { Kerr, Orange, } \\
\text { CA, USA }\end{array}$} \\
\hline & $\begin{array}{l}\text { Opaceous } \\
\text { dentin }\end{array}$ & $\begin{array}{l}\text { BG- } \\
\text { DT }\end{array}$ & $\begin{array}{l}\mathrm{A} 2, \mathrm{~A} 3, \mathrm{~A} 3.5, \mathrm{~B} 0, \mathrm{C} 2 \\
\mathrm{D} 2\end{array}$ & $\begin{array}{l}72 \text { vol. \% }(87 \text { wt.\%) of } \\
\text { barium aluminosilicate } \\
\text { glass filler }(10 \mu \mathrm{m}, 0.4 \\
\mu \mathrm{m} \text { and } 50 \mathrm{~nm}) ; \text { Bis- } \\
\mathrm{GMA}\end{array}$ & \\
\hline & $\begin{array}{l}\text { Transluce } \\
\text { nt dentin }\end{array}$ & BG-TL & $\begin{array}{l}\text { A2, A3, A3.5, B0, C2, } \\
\text { D2 }\end{array}$ & $\begin{array}{l}63 \text { vol.\% }(78 \text { wt.\%) of } \\
\text { barium aluminosilicate } \\
\text { glass filler }(10 \mu \mathrm{m}, 0.4 \\
\mu \mathrm{m} \text { and } 50 \mathrm{~nm}) ; \text { Bis- } \\
\mathrm{GMA}\end{array}$ & \\
\hline \multirow[t]{3}{*}{$\begin{array}{l}\text { Sinfony } \\
\text { (SF) }\end{array}$} & Enamel & SF-EN & $\begin{array}{l}\text { E1, E2, E3, E4, E5 } \\
\text { Polar (E5P), E6 Sun } \\
\text { (E6S) }\end{array}$ & \multirow{3}{*}{$\begin{array}{l}25-45 \quad \text { wt. } \% \text { glass } \\
\text { powder; } 15-30 \text { wt. } \% \\
\text { dicyclopentyldimethyle } \\
\text { ne diacrylate; } \\
\begin{array}{l}15-30 \text { wt. } \% \text { diurethane } \\
\text { dimethacrylate }\end{array}\end{array}$} & \multirow[t]{3}{*}{$\begin{array}{l}\text { 3M ESPE, } \\
\text { St. Paul, MN, } \\
\text { USA }\end{array}$} \\
\hline & Dentin & SF-DT & $\begin{array}{l}\text { DA1, DA2, DA3, } \\
\text { DA3.5, DA4, DB1, } \\
\text { DB2, DB3, DB4, DC1, } \\
\text { DC2, DC3, DC4, DD2, } \\
\text { DD3, DD4 }\end{array}$ & & \\
\hline & $\begin{array}{l}\text { Transpare } \\
\text { nt opal }\end{array}$ & SF-TL & $\begin{array}{l}\text { T1 Natural (T1N), T2 } \\
\text { Yellow (T2Y), T3 Blue } \\
\text { (T3B), T4 Gray (T4G) }\end{array}$ & & \\
\hline
\end{tabular}

Bis-GMA: Bisphenol A glycidyldimethacrylate

TEGDMA: Triethylene glycol dimethacrylate

UDMA: Urethane dimethacrylate

Figure 1- Shades and shade groups of resin composites investigated
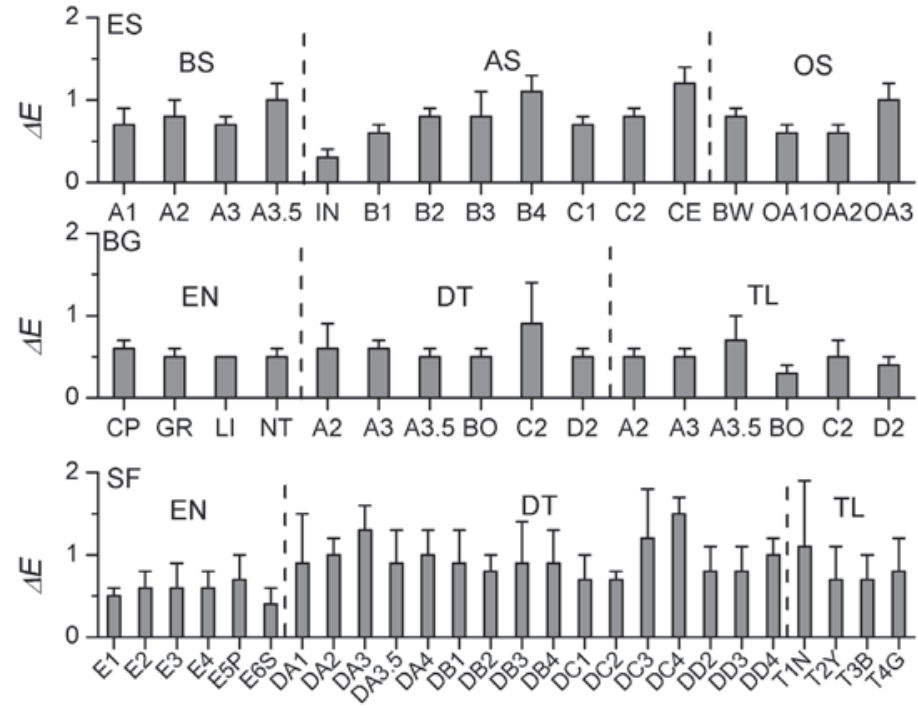

Figure 2- Color changes after 5,000 cycles of thermocycling 
0.1 (mean: $-0.2 \pm 0.3$ ) and -0.9 to 0.2 units (mean: $-0.3 \pm 0.3$ ) for $E S, B G$ and SF material, respectively (Figure 5).

Differences in $\Delta \mathrm{E}, \Delta \mathrm{L}, \Delta \mathrm{a}$ and $\Delta \mathrm{b}$ values by the type and shade group of resin composites are presented in Table 1. Based on t-test, indirect and direct resin composites showed no significant difference in $\Delta E$ values ( $p>0.05)$; however, they showed significant differences in $\Delta \mathrm{L}, \Delta \mathrm{a}$ and $\Delta b$ values $(p<0.05)$. Based on Scheffe's post hoc test, $\Delta \mathrm{E}$ values of indirect resin composites were influenced by the shade group: EN (mean $\Delta \mathrm{E}=0.6)=\mathrm{TL}($ mean $\Delta \mathrm{E}=0.6)<\mathrm{DT}($ mean $\Delta \mathrm{E}=0.9)$ $(\mathrm{p}<0.05)$.

For indirect resin composites, based on threeway ANOVA, $\triangle E$ values were influenced by the brand, shade group and shade designation; $\Delta \mathrm{L}$ values were influenced by the brand and shade group, but not by the shade designation; $\Delta a$ values were influenced by the brand and shade designation, but not by the shade group; $\Delta b$ values were influenced by the shade group and shade designation, but not by the brand $(p=0.05)$.

Table 1- Difference in the changes in color and color coordinates $(\Delta \mathrm{E}, \Delta \mathrm{L}, \Delta \mathrm{a}$ and $\Delta \mathrm{b})$ by the shade group of the materials

\begin{tabular}{|c|c|c|c|c|c|}
\hline \multirow[t]{2}{*}{ Parameter } & \multirow[t]{2}{*}{ Direct resin } & \multicolumn{2}{|c|}{ Indirect resin } & \multirow[t]{2}{*}{ Difference $^{*}$} & \multirow[t]{2}{*}{ Statistical method } \\
\hline & & BG & SF & & \\
\hline \multirow[t]{4}{*}{$\Delta \mathrm{E}$} & $\begin{array}{l}\text { ES-BA (1), } \\
\text { ES-AS (2), } \\
\text { ES-OS (3) }\end{array}$ & $\begin{array}{l}\text { BG-EN (4), } \\
\text { BG-DT (5), } \\
\text { BG-TL (6) }\end{array}$ & $\begin{array}{l}\text { SF-EN (7), } \\
\text { SF-DT (8), } \\
\text { SF-TL (9) }\end{array}$ & $\begin{array}{c}6,4,7,5,3,2,1,9 / \\
5,3,2,1,9,8\end{array}$ & $\begin{array}{l}\text { One-way ANOVA and } \\
\text { Scheffe's post hoc test }\end{array}$ \\
\hline & $\begin{array}{l}\text { ES-BA (1), } \\
\text { ES-AS (2), } \\
\text { ES-OS (3) }\end{array}$ & \multicolumn{2}{|c|}{ EN (4), DT (5), TL (6) } & $4,6,3,2,1 / 6,3,2,1,5$ & \\
\hline & ES (1) & BG (2) & SF (3) & $2 / 1,3$ & \\
\hline & ES (1) & BGSF (2) & & 2,1 & t-test \\
\hline \multirow[t]{4}{*}{$\Delta \mathrm{L}$} & $\begin{array}{l}\text { ES-BA (1), } \\
\text { ES-AS (2), } \\
\text { ES-OS (3) }\end{array}$ & $\begin{array}{l}\text { BG-EN (4), } \\
\text { BG-DT (5), } \\
\text { BG-TL (6) }\end{array}$ & $\begin{array}{l}\text { SF-EN (7), } \\
\text { SF-DT (8), } \\
\text { SF-TL (9) }\end{array}$ & $\begin{array}{c}4,5,6,3,1 / 6,3,1,2 / 1,2,9 \\
/ 2,9,7 / 9,7,8\end{array}$ & $\begin{array}{l}\text { One-way ANOVA and } \\
\text { Scheffe's post hoc test }\end{array}$ \\
\hline & $\begin{array}{l}\text { ES-BA (1), } \\
\text { ES-AS (2), } \\
\text { ES-OS (3) }\end{array}$ & \multicolumn{2}{|c|}{ EN (4), DT (5), TL (6) } & $3,1,6,4,2 / 1,6,4,2,5$ & \\
\hline & ES (1) & BG (2) & SF (3) & $2 / 1 / 3$ & \\
\hline & ES (1) & BGSF (2) & & $1 / 2$ & t-test \\
\hline \multirow[t]{4}{*}{$\Delta a$} & $\begin{array}{l}\text { ES-BA (1), } \\
\text { ES-AS (2), } \\
\text { ES-OS (3) }\end{array}$ & $\begin{array}{l}\text { BG-EN (4), } \\
\text { BG-DT (5), } \\
\text { BG-TL (6) }\end{array}$ & $\begin{array}{l}\text { SF-EN (7), } \\
\text { SF-DT (8), } \\
\text { SF-TL (9) }\end{array}$ & $\begin{array}{c}9,5,4,6,2,8 / 4,6,2,8,1 / \\
6,2,8,1,7 / 3\end{array}$ & $\begin{array}{l}\text { One-way ANOVA and } \\
\text { Scheffe's post hoc test }\end{array}$ \\
\hline & $\begin{array}{l}\text { ES-BA (1), } \\
\text { ES-AS (2), } \\
\text { ES-OS (3) }\end{array}$ & \multicolumn{2}{|c|}{ EN (4), DT (5), TL (6) } & $6,5,4,2 / 5,4,2,1 / 3$ & \\
\hline & ES (1) & $\mathrm{BG}(2)$ & SF (3) & $2 / 3 / 1$ & \\
\hline & ES (1) & BGSF (2) & & $2 / 1$ & t-test \\
\hline \multirow[t]{4}{*}{$\Delta \mathrm{b}$} & $\begin{array}{l}\text { ES-BA (1), } \\
\text { ES-AS (2), } \\
\text { ES-OS (3) }\end{array}$ & $\begin{array}{l}\text { BG-EN (4), } \\
\text { BG-DT (5), } \\
\text { BG-TL (6) }\end{array}$ & $\begin{array}{l}\text { SF-EN (7), } \\
\text { SF-DT (8), } \\
\text { SF-TL (9) }\end{array}$ & $\begin{array}{c}1,2,3,8 / 8,4,6,7,5 / \\
4,6,7,5,9\end{array}$ & $\begin{array}{l}\text { One-way ANOVA and } \\
\text { Scheffe's post hoc test }\end{array}$ \\
\hline & $\begin{array}{l}\text { ES-BA (1), } \\
\text { ES-AS (2), } \\
\text { ES-OS (3) }\end{array}$ & \multicolumn{2}{|c|}{ EN (4), DT (5), TL (6) } & $1,2,3 / 3,5 / 5,4,6$ & \\
\hline & $\mathrm{ES}(1)$ & BG (2) & SF (3) & $1 / 3 / 2$ & \\
\hline & ES (1) & BGSF (2) & & $2 / 1$ & t-test \\
\hline
\end{tabular}

* All the statistical results were based on the significance level of 0.05

' $l$ ' indicates the significant difference marker 

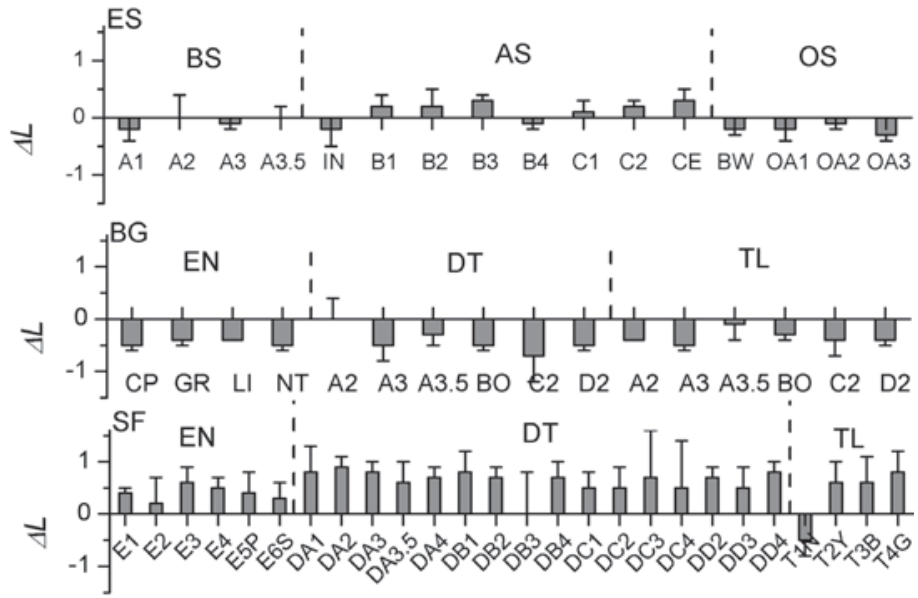

Figure 3- Changes in CIE $L^{*}$ after 5,000 cycles of thermocycling
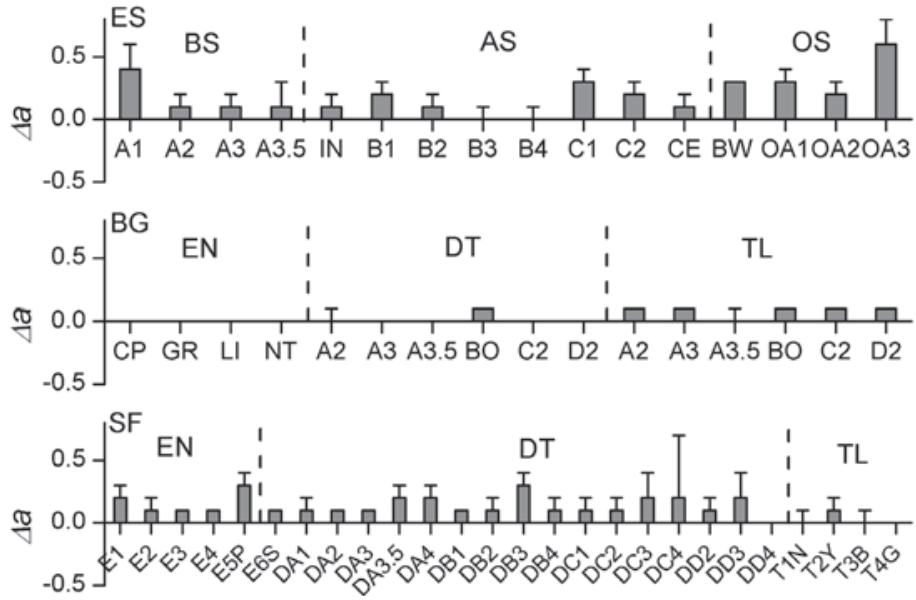

Figure 4- Changes in CIE $a^{*}$ after 5,000 cycles of thermocycling

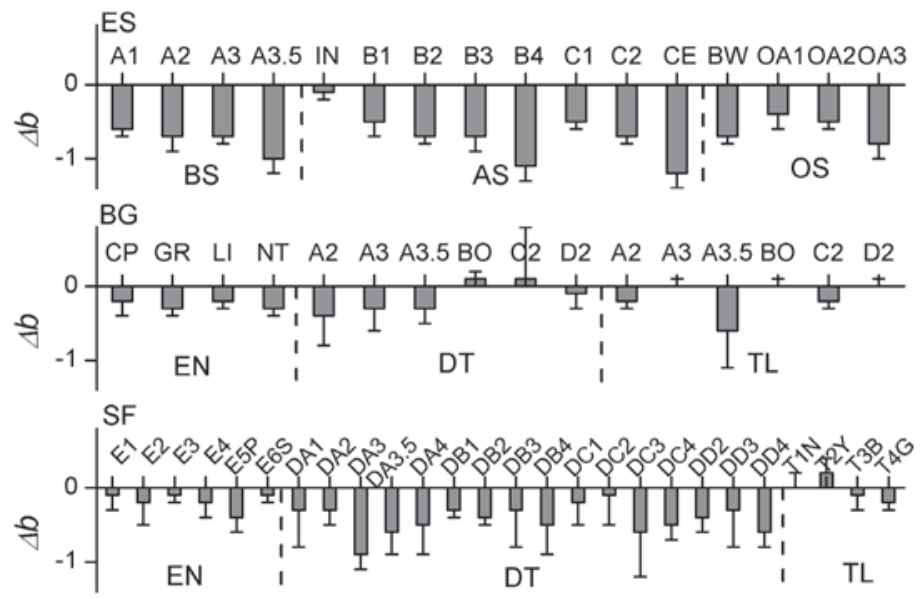

Figure 5- Changes in CIE $b^{*}$ after 5,000 cycles of thermocycling

\section{DISCUSSION}

A wide array of color stability studies of indirect resin composites were focus on accelerated aging by using weathering devices ${ }^{7,26,28}$. In one study ${ }^{7}$, after $300 \mathrm{~h}$ of accelerated aging, color changes of the indirect resin composites ranged between
0.6 and $3.4 \Delta \mathrm{E}$ units, and all indirect resins tested demonstrated color stability at or below a quantitative level that would be considered clinically acceptable. In another study ${ }^{28}$, color stability study of indirect resin composites after $383 \mathrm{~h}$ of accelerated aging, color changes were varied by the brand of material and the highest $\Delta E$ value was 4.3 units. In the present study, the 
color changes of indirect resin composites were in the range of 0.3 to $1.5 \Delta \mathrm{E}$ units after 5,000 cycles of thermocycling, which was generally lower than those of the previous studies. Although the manufacturer of the weathering device, used in the previously cited studies, estimates that $300 \mathrm{~h}$ of weathering is equivalent to one year of service, there was a concern whether an outdoor simulation such as weathering would translate to intraoral conditions ${ }^{7}$. Therefore, thermocycling instead of a weathering device can be regarded as more clinically relevant, and direct comparisons between the accelerated aging results using weathering devices and thermocycling could not be made.

Based on a color stability study of 8 brand of direct resin composites (41 shades) after 5,000 cycles of thermocycling, color changes were in the range of 1.1 to $4.6 \Delta \mathrm{E}$ units, which were influenced by the brand of resin composite ${ }^{18}$. In the present study, after 5,000 cycles of thermocycling, color changes of the indirect resin composites were in the range of 0.3 to $1.5 \Delta \mathrm{E}$ units, and were influenced by the brand, shade group and shade designation while the color changes of the direct resin composites were in the range of 0.3 to $1.2 \Delta \mathrm{E}$ units, which were generally smaller than those of the previous study ${ }^{18}$. Since the color change after thermocycling may be correlated with degradation, stain accumulation, water sorption and others ${ }^{20}$, difference in the color changes of resin composites should have been influenced by their different matrix and filler compositions. However, based on the results of the present study, it was a surprising fact that there was no significant difference in the $\Delta \mathrm{E}$ values of direct and indirect resin composites since indirect resin composites are generally regarded to have better color stability than direct resin composites due to their higher conversion degree. As to the changes in color coordinates, although $\Delta \mathrm{L}, \Delta \mathrm{a}$ and $\Delta \mathrm{b}$ values showed significant difference by the type of resin composites (Table $1)$, the values were very small. It was reported that a minimum CIELAB difference in color coordinates $(\Delta \mathrm{L}, \Delta \mathrm{a}$ and $\Delta \mathrm{b})$ of $1 \mathrm{CIE}$ unit would be perceptible to a human observer depending on the level of $L^{*}$ value, background color and lighting; differences in the 1 to 2 CIE units range would be noticeable to most observers ${ }^{1}$. In the present study, the $\Delta \mathrm{L}$, $\Delta \mathrm{a}$ and $\Delta \mathrm{b}$ values of the 42 shades of indirect resin composites were in the range of -0.9 to 0.9 CIE units; therefore, the changes would not perceptible to a human observer in most cases, and clinical implication of these differences would be very limited.

Within the indirect resin composites, $\Delta \mathrm{L}, \Delta \mathrm{a}$ and $\Delta b$ values were influenced by 2 combinations of 3 factors (brand, shade group and shade designation). With the exception of a few shades, nearly all the shades shifted to red (increased CIE $a *$ values) and blue (decreased CIE $b *$ values) after thermocycling (Figures 4 and 5). The increased redness indicates the influence of amine-based accelerators in the resin composites; since all amines are known to form by-products during photoreaction, which tend to cause yellow to redbrown discolorations under the influence of light or heat $3,18,20,21$. The decreased yellowness could be partly explained by the change of camphoroquinone content in the resin composites by the increased degree of polymerization. Camphoroquinone was used as a photoinitiator in most commercial resin composites, and the color of this initiator changed from yellow to almost colorless after polymerization reaction $3,18,20,21$. Since the conversion degree could not reach $100 \%$ and the polymerization reaction was not sufficient in resin composites, a certain extent of yellow color was remained, and the yellow color decreased due to the physicochemical reactions induced by the thermal changes during thermocycling process $3,18,20,21$. Furthermore, since indirect resin composites possess higher conversion degree, they showed less changes in CIE $a^{*}$ and $b^{*}$ values as compared to direct resin composites in the present study. Almost all the shades of BG material became darker (decreased CIE $L *$ values) after thermocycling; however, almost all the shades of SF material became brighter (increased CIE $L^{*}$ values) after thermocycling. Lightness change is an indicator for increased water sorption during thermocycling which influenced the refractive index of the resin matrix ${ }^{3,18,20,21}$. The reason for the discrepancies of the shade dependent changes in CIE $L^{*}, a^{*}$ and $b^{*}$ values might be due to the different matrix composition and filler content of the resin composites, since both the matrix composition and the filler content played important roles in the color stability of resin composites ${ }^{9}$.

Since the direction and magnitude of the color changes differed for the thermally and photochemically induced color changes, it seemed that varied mechanisms were involved in color change of resin composites ${ }^{5}$. However, regardless of the aging protocols, color shift, chroma change and hue difference were observed in resin composites ${ }^{10,19}$. It was reported that lighter or less chromatic shades tended to show larger color changes than more chromatic or darker shades ${ }^{13,26}$, and higher CIE $a^{*}$ and $b^{*}$ values had a negative influence on the color change after aging ${ }^{22}$. However, the results were different in the indirect resin composites of the present study. In our study, color changes were significantly different by the shade group such as enamel shades, dentin shades and translucent shades. After thermocycling, the darkest shade group (dentin shades) showed the highest color change while the enamel shades and translucent 
shades showed similar color changes. These results might reflect that the color change of indirect resin composites was influenced not only by the color coordinate but also by the translucency. Further studies on the influence of translucency on the color change of resin composites should be performed.

Based on the results of the present study, the first null hypothesis of the present study that the color stability of direct and indirect resin composites would be different was partly rejected because the type of resin composites did not influenced the DE values themselves; however, $\Delta \mathrm{L}, \Delta \mathrm{a}$ and $\Delta \mathrm{b}$ values were influenced by the type of resin composites. The second null hypothesis that the color change of resin composites after aging would be not be acceptable $(\Delta \mathrm{E}>3.3)$ was rejected because the color change of the three materials was in the range of 0.3 to $1.5 \Delta \mathrm{E}$ units. The third null hypothesis that the color changes after aging in indirect resin composites would not be influenced by the brand, shade group and shade designation in each shade group was also rejected because color change was influenced by the three factors.

\section{CONCLUSIONS}

Within the limitations of the present study, it may be concluded that changes in color and color coordinates of contemporary direct and indirect resin composites after 5,000 cycles of thermocycling were clinically acceptable. There was no significant difference in the changes in color of direct and indirect resin composites after thermocycling. However, the changes in the lightness, red-green and yellow-blue coordinates were influenced by the type of resin composites. Therefore, these differences should be considered in clinical practice when repairing or restoring the same or neighboring teeth with different kinds of resin composites.

\section{REFERENCES}

1- Berger-Schunn A. Practical color measurement: a primer for the beginner, a reminder for the expert. New York: Wiley; 1994. 2- Blank JT. Scientifically based rationale and protocol for use of modern indirect resin inlays and onlays. J Esthet Dent. 2000;12:195-208.

3- Choi MS, Lee YK, Lim BS, Rhee SH, Yang HC, Lim YJ. Changes in color and translucency of porcelain repairing resin composites after thermocycling. J Biomed Mat Res B Appl Biomater. 2006;78:1-6. 4- CIE (Commission Internationale de I'Eclairage). Colorimetry - technical report. N.15. $3^{\text {rd }}$ edition. Vienna: Bureau Central de la CIE; 2004.

5- Cook WD, Chong MP. Color stability and visual perception of dimethacrylate based dental composite resins. Biomaterials. $1985 ; 6: 257-64$
6- Dietschi D, Campanile G, Holtz J, Meyer JM. Comparison of the color stability of ten new-generation composites: an in vitro study. Dent Mater. 1994;10:353-62.

7- Douglas RD. Color stability of new-generation indirect resins for prosthodontic application. J Prosthet Dent. 2000;83:166-70. 8- Douglas RD, Brewer JD. Acceptability of shade differences in metal ceramic crowns. J Prosthet Dent. 1998;79:254-60.

9- Faltermeier A, Behr M, Mussig D. In vitro color stability of aesthetic brackets. Eur J Orthod. 2007;29:354-8.

10- Fruits TJ, Duncanson MG Jr, Miranda FJ. In vitro weathering of selected direct esthetic restorative materials. Quintessence Int. $1997 ; 28: 409-14$.

11- Giordano R $2^{\text {nd }}$. Fiber reinforced composite resin systems. Gen Dent 2000;48:244-9.

12- Güler AU, Güler E, Yücel AC, Ertaş E. Effects of polishing procedures on color stability of composite resins. J Appl Oral Sci. 2009;17:108-12.

13- Hosoya Y. Five-year color changes of light-cured resin composites: influence of light-curing times. Dent Mater. 1999; 15:268-74.

14- Janda R, Roulet JF, Kaminsky M, Steffin G, Latta M. Color stability of resin matrix restorative materials as a function of the method of light activation. Eur J Oral Sci. 2004;112:280-5.

15- Johnston WM, Reisbick MH. Color and translucency changes during and after curing of esthetic restorative materials. Dent Mater. 1997;13:89-97.

16- Knobloch LA, Kerby RE, Clelland N, Lee J. Hardness and degree of conversion of posterior packable composites. Oper Dent. 2004;29:642-9.

17- Kolbeck C, Rosentritt M, Lang R, Handel G. Discoloration of facing and restorative composites by UV-irradiation and staining food. Dent Mater. 2006;22:63-8.

18- Lee SH, Lee YK. Effect of thermocycling on optical parameters of resin composites by the brand and shade. Am J Dent. 2008;21:361-7.

19- Lee YK, El Zawahry M, Noaman KM, Powers JM. Effect of mouthwash and accelerated aging on the color stability of esthetic restorative materials. Am J Dent. 2000;13:159-61.

20- Lee YK, Lim BS, Rhee SH, Yang HC, Powers JM. Changes of optical properties of dental nano-filled resin composites after curing and thermocycling. J Biomed Mat Res B Appl Biomater. $2004 ; 71: 16-21$.

21- Lee YK, Lim BS, Rhee SH, Yang HC, Powers JM. Color and translucency of A2 shade resin composites after curing, polishing and thermocycling. Oper Dent. 2005;30:436-42.

22- Lee YK, Powers JM. Color and optical properties of resin-based composites for bleached teeth after polymerization and accelerated aging. Am J Dent. 2001;14:349-54.

23- Powers JM, Dennison JB, Koran A. Color stability of restorative resins under accelerated aging. J Dent Res. 1978;57:964-70.

24- Rosentritt M, Esch J, Behr M, Leibrock A, Handel G. In vivo color stability of resin composite veneers and acrylic resin teeth in removable partial dentures. Quintessence Int. 1998;29:517-22. 25- Ruyter IE, Nilner K, Moller B. Color stability of dental composite resin materials for crown and bridge veneers. Dent Mater. $1987 ; 3: 246-51$.

26- Schulze KA, Tinschert J, Marshall SJ, Marshall GW. Spectroscopic analysis of polymer-ceramic dental composites after accelerated aging. Int J Prosthodont. 2003;16:355-61.

27- Stober T, Gilde H, Lenz P. Color stability of highly filled composite resin materials for facings. Dent Mater. 2001;17:87-94. 28- Zanin FR, Garcia LF, Casemiro LA, Pires-de-Souza FC. Effect of artificial accelerated aging on color stability and surface roughness of indirect composites. Eur J Prosthodont Restor Dent. 2008; $16: 10-4$ 